\title{
Metastatic Cutaneous Melanoma
}

National Cancer Institute

\section{Source}

National Cancer Institute. Metastatic Cutaneous Melanoma. NCI Thesaurus. Code C156072.

A melanoma that arises from the skin and has metastasized to another anatomic site. 